\title{
Evaluation of energy delivery by electric vehicle approximated by horizontal and vertical power consumption rates with geographic information
}

\author{
Kenta Tanoue $^{\mathrm{a}}$, Atsushi Shiota ${ }^{\mathrm{a}}$, Yasunori Mitani ${ }^{\mathrm{a}}$, Yaser Qudaih ${ }^{\mathrm{a}}$, Kiyotaka Fuji ${ }^{\mathrm{b}}$ \\ ${ }^{a}$ Dept. Electrical and Electronic Eng. Kyushu Institute of Technology, Japan \\ ${ }^{b}$ Dept. Bological Functions Eng. Kyushu Institute of Technology, Japan
}

\begin{abstract}
The frequent occurrence of natural disasters is relating to the environmental issues under the influence of global warming. Occasionally blackouts are caused by natural disasters, therefore, we should study how to secure power sources supplies at the time of the power system loss in the event of disaster. On the other hand, in the automotive industry, Electric Vehicles (EV) are introduced into the market for reducing $\mathrm{CO}_{2}$ which is one of the factors of global warming. In addition, EV can give power through an inverter from the batteries. The aim of this research is to develop the navigating system for energy delivery based on Geographic Information System (GIS) utilizing electric vehicles as a "moving batteries" to back-up the power distribution system. Then, it is important to grasp how much electric energy in EV's battery is available after running to the refugee locations. In this paper the approximation of power consumption for EV driving considering geographic information such as elevation and distance has been focused on. The results are promising as an additional efforts to provide emergency plans to power system in the up normal situations.
\end{abstract}

Keywords: GIS, EV, power system restoration battery storage

\section{Introduction}

In Japan, in December, 2014, about 1,500 people have been fully isolated under the influence caused by the local heavy snow in Tokushima area. The IP telephone using internet lines which spread in almost all over the area, reaching every family, were not able to be used as a result of power supply isolation in that area. Therefore, rescue operations ran into difficulties because safety confirmation was not possible. In addition, there was the damage that some victims who lived in all-electric home could not be heated as they became not being able to use heaters at the time of local heavy snow. To respond to such situation, the facilities are in a need of an independent electricity supply at the time of blackout caused by the disaster. Hence, secure power technique is demanded without depending on the electric power system.

On the other hand, the number of electric vehicles has been recently increased in Japan [1]. With applying an inverter, it is possible to deliver electric power from EV battery storage to facilities. Our approach is to construct a system to efficiently use the mobile batteries of the EV in terms of the area, size and location. As power generating facilities, dispersed power generation in Fukuoka prefecture has been selected which belongs to Fukuoka Environment Bureau. This power supply facility is possible to generate power independently from the power grid or household Photovoltaic (PV). Moreover, there is a research that EV can charge energy from any conventional photovoltaic (PV) system with bidirectional DC/DC converter [2]-[4]. So, residential PV systems also can be regarded as power supply facilities for the EV charging.

\footnotetext{
* Manuscript received April 1, 2015; revised August 26, 2015.

Corresponding author. Tel.:+81-80-1543-1209; E-mail address: k108068k@mail.kyutech.jp.

doi: $10.12720 /$ sgce.4.3.276-281
} 
EVs have the mission of the short driving range. When the dispersed generators deliver power by EV, it has to be transported efficiently from the power supply facility to the targeted locations. To transport and deliver the power of the EV, it is necessary to grasp the round trip and the exact route to the destination compared with the battery capacity of the EV. Therefore, this research focuses on driving power consumption approximation utilizing and considering the geographic information.

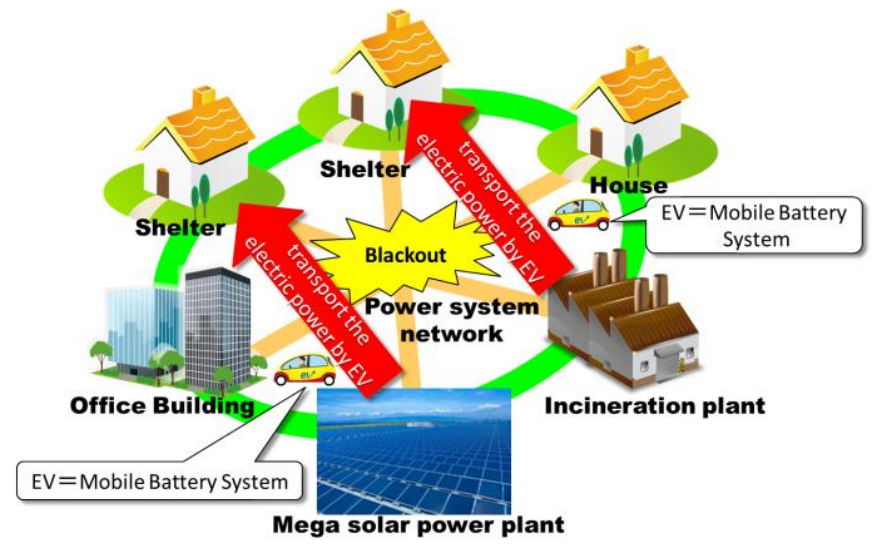

Fig. 1. General diagram of the studied system.

\section{Estimating Consumption Power of EV}

\subsection{Research overview}

This research, transporting the electric power by using EV, focuses on estimating amount of electric power which EV can supply to the facility at the time of arrival to it. This amount can be calculated by subtracting amount of driving power consumption from remaining battery capacity at the time of the departure of the charge spot. In other words, estimating amount of driving power consumption means estimating amount of power which people can use in home or a refugee shelters.

Our research focuses using GIS on the estimating amount of driving power consumption. The reason for this is GIS can take in a variety of information associating with geographic information and perform arrangement unification, expression, analysis and so on. Moreover, information can be registered in real time. For example, some people can access information of impassable road into GIS and it does previously noted function. Based on these features, the authors have developed the new method of Power Transport Mapping Method (PTMM) to determine all required information in the map using GIS [5], [6]. PTMM is free to modify the approximation function of the driving power consumption. It is a mechanism that can accommodate a variety of vehicle types by modifying the function. In this research, the approximation function of the driving power consumption is introduced for i-MiEV typeG of Mitsubishi Motors Corporation [7]. Appearance of the used i-MiEV is shown in Fig. 2.

\subsection{Estimation of EV consumption with power effective cost}

According to the report of Chubu Electric Power Company, the average power effective cost of the "Mitsubishi i-MiEV" is $7.3 \mathrm{~km} / \mathrm{kWh}$ [8]. Therefore, the driving power consumption for i-MiEV $(W)$ $[\mathrm{kWh}]$ is expressed by following equation (1).

$$
W=\frac{x}{7300}
$$

where $x$ is travelling distance[m]. $W$ is the driving power consumption [kWh]. By PTMM and using equation (1), EV consumed the electric power capacity map was developed at Kitakyushu City 
Environment Bureau Hiagari plant. This plant is the starting point because it has an independent generator. The constructed EV consumed electric power capacity map is shown in Fig. 3

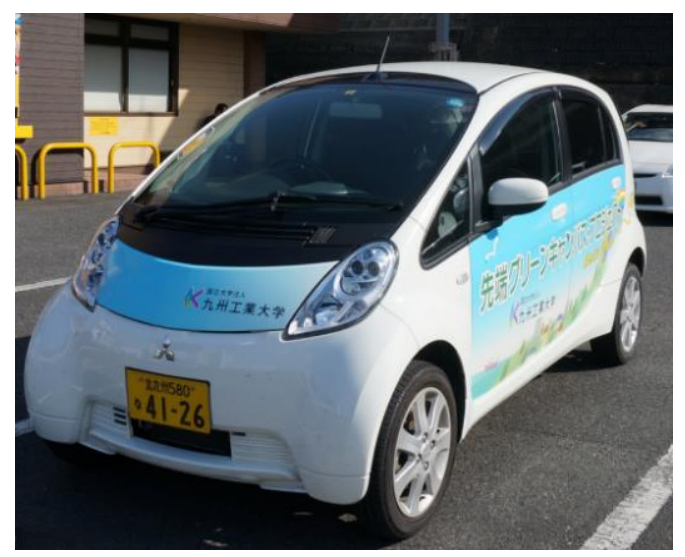

Fig. 2. i-MiEV type G.

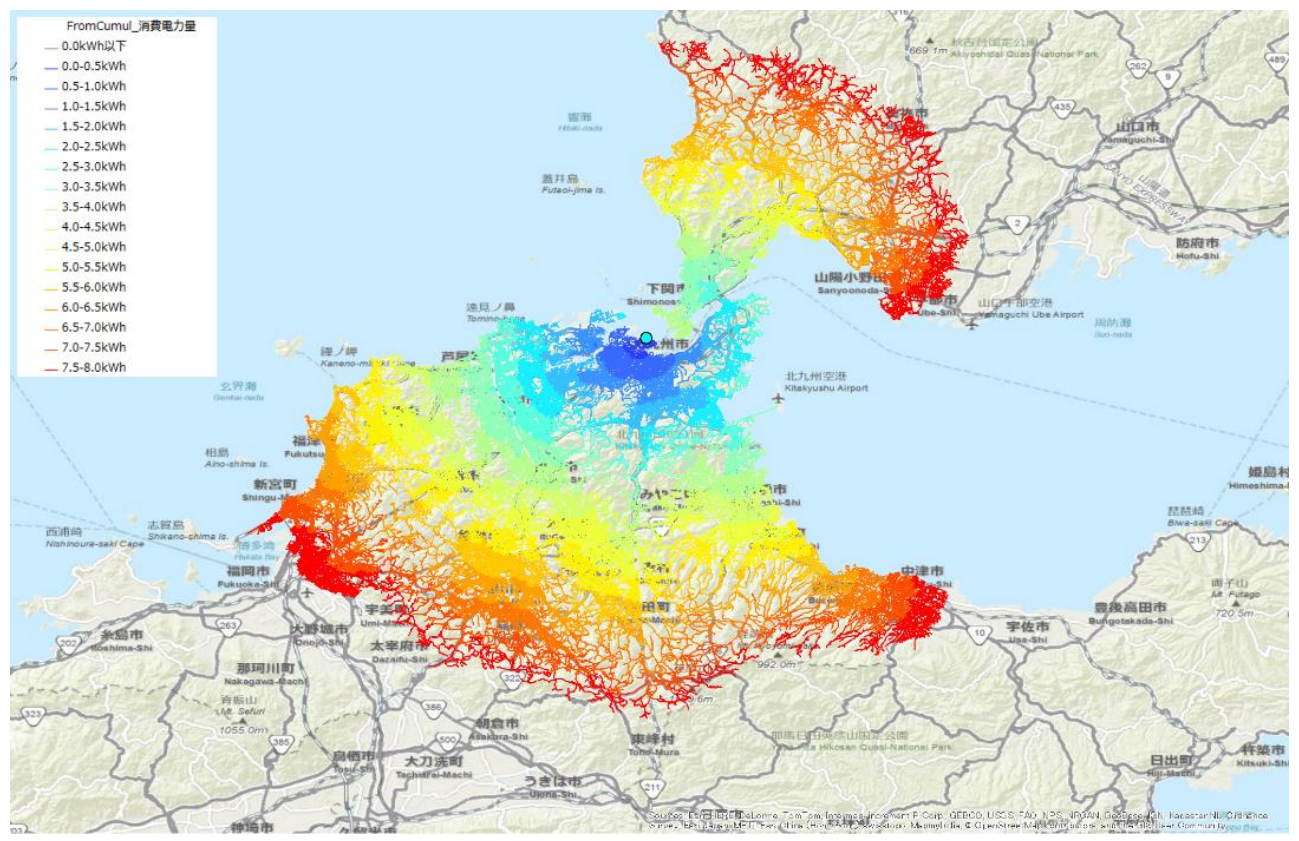

Fig. 3. The electric power capacity map with consumed EV using power effective cost.

Table 1. Estimated error and actual power consumption

\begin{tabular}{|c|c|c|c|c|c|}
\hline Route & $\begin{array}{c}\text { Travel distance } \\
{[\mathrm{m}]}\end{array}$ & $\begin{array}{c}\text { Distance in } \\
\text { elevation }[\mathrm{m}]\end{array}$ & $\begin{array}{c}\text { Estimated power } \\
\text { consumption }[\mathrm{kWh}]\end{array}$ & $\begin{array}{c}\text { Actual power } \\
\text { consumption }[\mathrm{kWh}]\end{array}$ & $\begin{array}{c}\text { error } \\
{[\mathrm{kWh}]}\end{array}$ \\
\hline A & 27,600 & 1.6 & 3.78 & 3.24 & 0.54 \\
\hline B & 24,500 & 9 & 3.36 & 3.38 & -0.02 \\
\hline C & 17,800 & 8.9 & 2.44 & 1.93 & 0.51 \\
\hline D & 30,200 & 36.3 & 4.14 & 4.15 & -0.01 \\
\hline E & 6,200 & 498 & 0.85 & 2.80 & -1.95 \\
\hline
\end{tabular}

In Fig. 3, the driving power consumption spreads through the concentric circle around Hiagari plant. The colors are painted in units of $0.5 \mathrm{kWh}$ and the outermost of maps is the area where EV can reach to 
consume 7.5-8.0 $\mathrm{kWh}$ (red). However, there is the problem that errors are large when EV drives on the undulant roads. The example data are shown in Table 1.

The driving power consumption which is considered and are not different by Table 1. This will be detailed in the following section.

\subsection{Estimation of EV consumption considering the elevation}

For solving the mention problem, the driving power consumption which is considered the elevation. The proposed solution is divided the driving power consumption into a horizontal direction and a vertical direction. In other words, the proposed driving power consumption for i-MiEV $(W)$ is expressed by the equation (2).

$$
\mathrm{W}=W_{x}+W_{h}
$$

This conceptual diagram is shown in the Fig. 4.

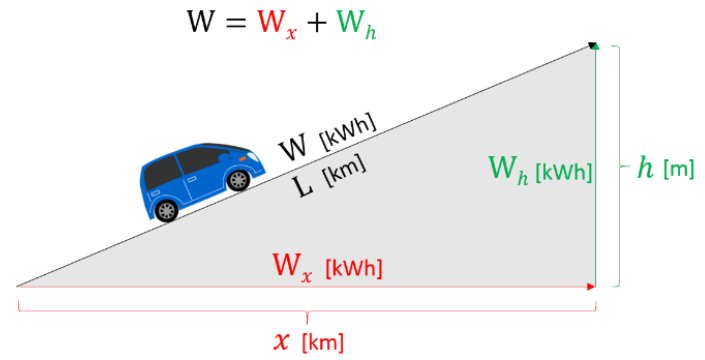

Fig. 4. The conceptual diagram of EV's driving power consumption.

In Fig. 4, the total driving power consumption $(W)$ is measured by a wattmeter. The horizontal distance $(x)$ and the altitude $(h)$ are also measurable by GIS. The travelled distance $(L)$ and the horizontal distance $(x)$ of EV almost are considered as the same direction because the roads of Japan are constructed within 5.1 degree (9\%). Assuming that the horizontal average power effective cost of "Mitsubishi i-MiEV" is 7.3 $\mathrm{km} / \mathrm{kWh}$, the horizontal driving power consumption $\left(W_{x}\right)$ are calculated with equation (1).

$$
W_{x}=\frac{x}{7300}
$$

Therefore, the vertical driving power consumption $\left(W_{h}\right)$ are calculated by the following equation (4).

$$
W_{h}=W-W_{x}
$$

After calculating $W_{h}$, i-MiEV's total driving power consumption are able to simulated by $x$ and $h$ if the relationship between $W_{h}$ and $h$ is determine.

From the above mention,, measured driving power consumption are processed in the following procedures.

(1) It calculates the amount of the total power consumption on each driven road.

(2) It calculates the horizontal driving power consumption $\left(W_{x}\right)$, by dividing the travelled distance by the horizontal average power effective cost of "Mitsubishi i-MiEV" $7.3 \mathrm{~km} / \mathrm{kWh}$.

(3) It calculates the vertical driving power consumption $\left(W_{h}\right)$, subtracting the horizontal driving power consumption $W_{x}$, from the amount of the total power consumption.

(4) After measuring the difference in the elevation $(h)$ between the start point and the end point of the driven road by using GIS, the difference in the elevation is plotted on a horizontal axis and the vertical driving power consumption $\left(W_{h}\right)$ is plotted on a vertical axis.

The graph which is made in procedure (4) is shown in the Fig. 5. 


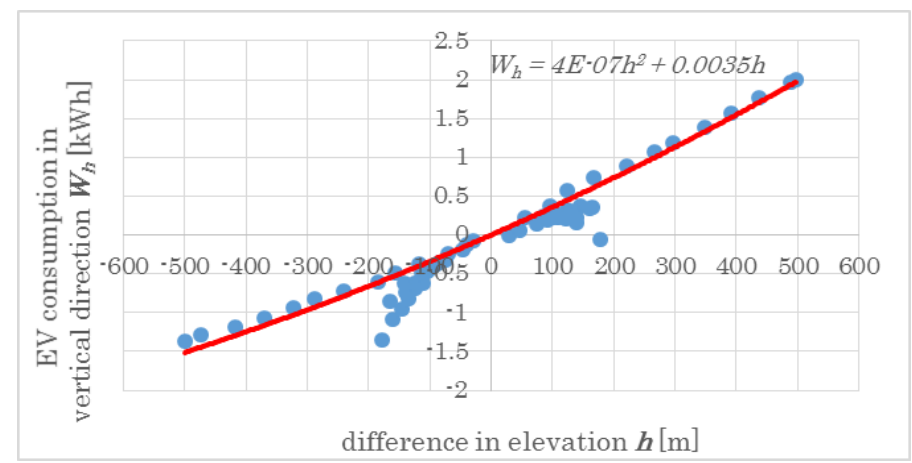

Fig. 5. Correlation diagram of the vertical driving power consumption $W_{h}$ and the difference in elevation $h$.

In Fig. 5, the proximate curve leads to the following expression.

$$
W_{h}=\left(4 \times 10^{-7}\right) h^{2}+0.0035 h
$$

Using the equation (5), the vertical driving power consumption $\left(W_{h}\right)$ is calculated from a difference in the elevation $(h)$. Therefore, substituting to equation (3) and the equation (5) into the equation (2), the approximation of i-MiEV's driving power consumption with geographic information is introduced.

$$
\mathrm{W}=\frac{x}{7300}+\left(4 \times 10^{-7}\right) h^{2}+0.0035 h
$$

By using PTMM and the equation (6), the constructed EV consumed the electric power capacity map is developed and shown in Fig. 6.

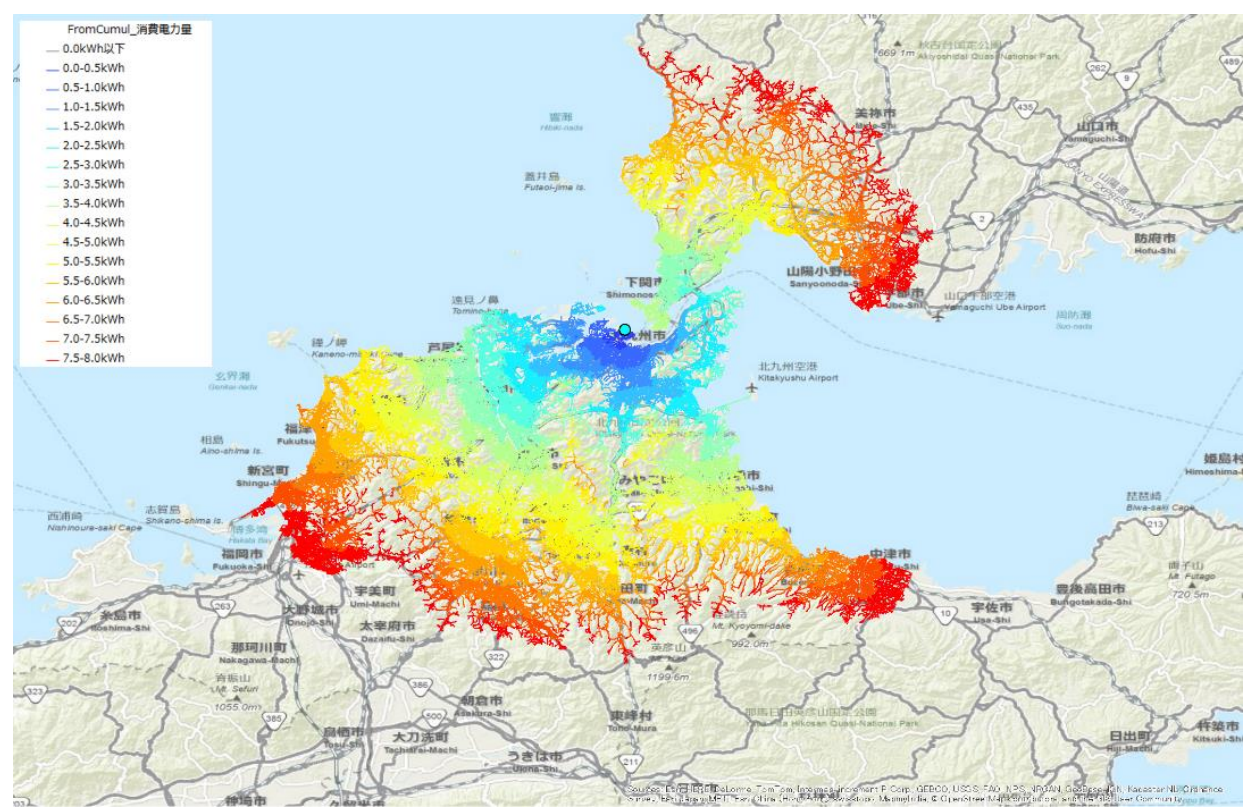

Fig. 6. The electric power capacity map with consumed EV considering, elevation.

Based on the comparison of Fig. 6 and Fig. 3, the electric power capacity map with consumed EV considering the elevation is less accessible area than without considering. This is the reason that Hiagari plant which is the center of the map is located in the lowest area around the field. In addition, the center of Fig. 6 turns red lines because this area is in mountain areas. In the same way as Table 1, the estimated 
power consumption with equation (6) and the actual power consumption are shown in Table 2.

Table 2. Estimated error and actual power consumption with the elevation

\begin{tabular}{|c|c|c|c|c|c|}
\hline Route & $\begin{array}{c}\text { Travel distance } \\
{[\mathrm{m}]}\end{array}$ & $\begin{array}{c}\text { Distance in } \\
\text { elevation }[\mathrm{m}]\end{array}$ & $\begin{array}{c}\text { Estimated power } \\
\text { consumption }[\mathrm{kWh}]\end{array}$ & $\begin{array}{c}\text { Actual power } \\
\text { consumption }[\mathrm{kWh}]\end{array}$ & $\begin{array}{c}\text { error } \\
{[\mathrm{kWh}]}\end{array}$ \\
\hline A & 27,600 & 1.6 & 3.79 & 3.24 & 0.55 \\
\hline B & 24,500 & 9 & 3.39 & 3.38 & 0.01 \\
\hline C & 17,800 & 8.9 & 2.47 & 4.93 & 0.54 \\
\hline D & 30,200 & 36.3 & 4.26 & 2.15 & 0.11 \\
\hline E & 6,200 & 498 & 2.69 & 2.80 & -0.11 \\
\hline
\end{tabular}

In Table 2, the error of route $\mathrm{E}$ can be smaller and errors of other routes are within the limits of 0.5 $\mathrm{kWh}$. It is conformed that the proposed method shows the best performance of estimated power consumption than the previous method.

\section{Conclusion}

In this research, the EV driving power consumption divides into the horizontal direction and the vertical direction. Consequently, the function of the driving power consumption approximation with geographic information for transporting electric power with EV as "moving batteries" in case of power failure due to a disaster have been constructed.

Using this approximation, the available power for the destination can be estimated and EV owners (e.g., local governments or dealers) are able to manage the power support effectively with EVs. It is necessary to increase the accuracy of the consumed electric power approximation function.

The future plan for this research includes that other vehicle types should be taken into account for achieving the better result.

\section{Acknowledgements}

This research was supported by the G-space City Construction Project of the Ministry of Internal Affairs and Communications at Kitakyushu City of Japan. The authors would like to thank to the research members for their kind assistance.

\section{References}

[1] Automobile Inspection \& Registration Information Association. (2014). Possession number change of the hybrid car and electric car. [Online]. Available: http://www.airia.or.jp/publish/statistics/ao1lkc00000000z4-att/03_7.pdf

[2] Takahisa K, Kiyotaka F, Atsushi S, Yasunori M, Yaser SQ. Construction of power supply system using electric vehicle for stable power delivery from PV generation. In: Proc. International Conferences on Smart Grid and Clean Energy Technology, 2014.

[3] Naoya K, Susumu T, Yukio O. DC link Battery and Power Supply System for efficient use of PV. The Institute of Electrical Engineers of Japan, 2012; C-9:135-136.

[4] Takahisa K, Kiyotaka F, Atsushi S, Yasunori M. A study of DC voltage control for smart photovoltaic system by connecting electric vehicle. In: Proc. 2nd International Symposium on Applied Engineering and Sciences, 2014.

[5] Atsushi S, Kenta T, Yasunori M, Yaser SQ, Kiyotaka F. Construction of transporting system the electric power by using EV as mobile battery system in during black out of power grid by disasters. In: Proc. International Conference on Electrical Engineering, 2015.

[6] Kiyotaka F, Shirai Y, Takahisa K, Atsushi S, Yasunori M. Functional PV-PCS power supply system using EV storage and GIS with the emergency mode. In: Proc. 2nd International Symposium on Applied Engineering and Sciences, 2014.

[7] Takashi H, Koji T, Hiroaki M. Development of i MiEV next-generation electric vehicle (Second report). Mitsubishi Motors Technical Review No.20, 2008.

[8] Chubu Electric Power Co., Ltd. (2012). Mitsubishi i-MiEV performance evaluation and effective application measures for achieving efficient energy usage and a low-carbon society. [Online]. Available: http://www.chuden.co.jp/resource/corporate/news_144_13.pdf 